\title{
The adenomatous polyposis coli tumour suppressor gene regulates c-MYC transcription in colon cancer cells
}

He TC, Sparks AB, Rago C, et al. Identification of c-MYC as a target of the APC pathway. Science 1998;281:1509-12.

\begin{abstract}
The adenomatous polyposis coli gene (APC) is a tumor suppressor gene that is inactivated in most colorectal cancers. Mutations of APC cause aberrant accumulation of $\beta$-catenin, which then binds $T$ cell factor-4 (Tcf-4), causing increased transcriptional activation of unknown genes. Here, the c-MYC oncogene is identified as a target gene in this signaling pathway. Expression of c-MYC was shown to be repressed by wild type APC and activated by $\beta$-catenin, and these effects were mediated through $\mathrm{Tcf}-4$ binding sites in the c-MYC promoter. These results provide a molecular framework for understanding the previously enigmatic overexpression of c-MYC in colorectal cancers.
\end{abstract}

\section{Comment}

More than $80 \%$ of colorectal tumours harbour mutations in the adenomatous polyposis coli $(A P C)$ tumour suppressor gene which encodes a $310 \mathrm{kDa}$ cytoplasmic protein with several structural and binding domains. ${ }^{1}$ One of its functions is to bind and degrade $\beta$-catenin, a promiscuous cytoskeletal protein, which associates with APC, E-cadherin (a cell-cell adhesion molecule), epidermal growth factor receptor, and two nuclear transcription factors (members of the Lef/Tcf family). ${ }^{2-4} \beta$-catenin and APC are bound in a multiprotein complex with two other proteins, a serine/threonine kinase enzyme GSK-3 $\beta$ that negatively regulates $\beta$-catenin and a newly discovered molecule, conductin (or axin), which assembles this complex. ${ }^{5}$ In normal colonic epithelial cells, $\beta$-catenin is either continuously degraded via its interaction with wild type APC or is localised at the adherens junctions as part of the E-cadherin complex. However, in colon cancer cells with genetic or epigenetic abnormalities of any component of this multiprotein complex, $\beta$-catenin is not degraded and tends to translocate to the nucleus ${ }^{6}$ where it interacts with transcription factors and thereby regulates gene expression. $^{7}$

To identify the genes regulated by $\beta$-catenin in colon cancer cells, He et al used the serial analysis of gene expression (SAGE) technique which allowed the quantitative analysis of short sequences ( 15 base pairs) of cellular mRNA turned on or off in response to $A P C$. Using $A P C$ induced and control colon carcinoma cells in vitro, they identified a large number of transcripts, of which 16 were repressed by the wild type $A P C$ gene and one of these was the c-MYC oncogene. This repression was confirmed at the mRNA and protein levels by northern and western blotting analysis. Further evidence of this rather unexpected finding came from a series of experiments where a DNA sequence containing the c-MYC promoter region was inserted upstream of a luciferase reporter gene and the construct was tested for responsiveness to $A P C$. As predicted, the c-MYC promoter conferred significant transcriptional activity that was inhibited by $A P C$ when it was introduced into colon carcinoma cells. Once again, the APC- $\beta$-catenin-Tcf pathway seemed to play an important role in this novel interaction. The researchers demonstrated that $\mathrm{c}-M Y C$ was significantly activated by a mutated $\beta$-catenin construct which was previously shown to render cells insensitive to downregulation by endogenous wild type $A P C$. The analysis of the c-MYC promoter sequence showed two potential Tcf binding sites which, when abrogated in vitro, lead to complete loss of $\beta$-catenin activation.

In conclusion, this study provides the first example of how mutations in a tumour suppressor gene such as $A P C$ can lead to activation of a dominant oncogene such as c- $M Y C$. In addition, it provides an explanation for the overexpression of c-MYC protein in colorectal tumours which has been well documented in a number of immunohistochemical studies. More importantly, these findings show that $\mathrm{c}-M Y C$ activation is a direct consequence of the perturbation of the APC- $\beta$-catenin axis in colorectal cancer and not just an epiphenomenon resulting from the increased proliferation characteristic of neoplastic cells. It will also be important to characterise the other transcripts which seem to be modulated by APC and perhaps these novel molecular interactions will lead to a further understanding of the natural history of colorectal cancer. In the near future, targeting of the $\mathrm{c}-M Y C-A P C$ pathway may be exploited to develop specific treatment for cancer based on its selective inactivation.

M PIGNATELLI
Division of Investigative Science,
Imperial College School of Medicine,
Hammersmith Campus,
Du Cane Rod,
London W12 ONN, UK
email: m.pignatelli@rpms.ac.uk

1 Groden J, Thliveris A, Samowitz W, et al. Identification and characterization of the familial adenomatous polyposis coli gene. Cell 1991;66:589-600. 2 Su L-K, Vogelstein B, Kinzler KW. Association of the APC tumor suppressor protein with catenins. Science 1993;62:1734-7.

3 Liu D, El-Hariry I, Karayiannakis AJ, et al. Phosphorylation of $\beta$-catenin and epidermal growth factor receptor by intestinal trefoil factor. Lab Invest 1997;77:557-63.

4 Behrens J, von Kries JP, Kuhl M, et al. Functional interaction of $\beta$-catenin with the transcription factor LEF-1. Nature 1996;382:638-42.

5 Sakanaka C, Weiss JB, Williams LT. Bridging of $\beta$-catenin and glycogen synthase kinase- 3 by axin and inhibition of $\beta$-catenin-mediated transcription. Proc Natl Acad Sci USA 1998;95:3020-3.

6 Valizadeh A, Karayiannakis AJ, El-Hariry I, et al . Expression of E-cadherinassociated molecules $(\alpha-, \beta-$, and $\gamma$-catenins and p120) in colorectal polyps. Am f Pathol 1997;150:902-7.

7 Korinek V, Barker N, Morin PJ, et al. Constitutive transcriptional activation by a $\beta$-catenin-Tcf complex in APC $^{-/-}$colon carcinoma. Science 1997;275:
$1784-7$. 